\title{
Synchronous planulation of Manicina areolata (Scleractinia) with lunar periodicity
}

\author{
Kenneth G. Johnson* \\ Geology Department, The University of Iowa, Iowa City, Iowa 52242, USA
}

\begin{abstract}
Field observations and histology were used to examine the reproductive ecology of the scleractinian coral Manicina areolata (Linneaus) from the San Blas Islands, Panama. $M$. areolata is a simultaneous hermaphrodite with brooded larvae. Planulation is synchronous and closely correlated with lunar phase, with most planulae released within $2 \mathrm{~d}$ of the new moon. In contrast to other brooding species, a short breeding season peaks during June and July. Colonies are not reproductive until they have reached a height of 1.5 to $2.0 \mathrm{~cm}$, after 2 to $3 \mathrm{yr}$ of growth. Planula production in mature colonies is on the order of hundreds to thousands of larvae per colony per year. Fecundity is not related to size after colonies become reproductive. Distribution of planula production is strongly skewed to the right, with $5 \%$ of the colonies producing over $30 \%$ of the larvae. These highly fecund colonies are not morphologically different from other colonies, and most likely represent annual or small-scale spatial variation (meters in extent) in reproductive effort or fertilization success. Studies of reproductive output in scleractinian corals must be adequately designed to account for such fine-scale variation, since analyses based on a few colonies may be inappropriate for estimating population larval production.
\end{abstract}

\section{INTRODUCTION}

Detailed basic information on the reproductive behavior of most scleractinian species remains unavailable (e.g. Richmond \& Hunter 1990), but there is a growing appreciation of the variety and complexity of scleractinian reproductive behaviors (Szmant 1986. Harrison \& Wallace 1990). Knowledge of the natural history of reef corals is not only central to understanding ecological and evolutionary patterns and processes, but is required for successful management of reef ecosystems in environments subject to increasing levels of human-induced stress.

This study documents the reproductive ecology of Manicina areolata (Linneaus), a meandroid free-living Caribbean reef-coral. The species is characterized by discrete colonies that do not remain attached to the substrate throughout life. Colonies are small (less than $25 \mathrm{~cm}$ in length) and are unlikely to propagate by fission or fragmentation. Fusion of individual colonies is common in the laboratory and also occurs in field

\footnotetext{
- Present address: Department of Palaeontology, The Natural History Museum, Cromwell Road, London SW7 5BD, UK
}

populations (Boschma 1929), but results in little or no change in the overall form of the colony. However, fused colonies are easily recognizable by the presence of 2 discrete valley systems in the colony meander pattern. Colonies of $M$. areolata are therefore free of many of the demographic problems associated with clonal animals that are subject to fragmentation and fusion, factors that considerably complicate study of the relationship between scleractinian life history and reproductive biology (Hughes \& Jackson 1985).

Manicina areolata is a simultaneous hermaphrodite, and ovaria and spermaria develop within the same mesentery (Peters 1984). Although colonies have been observed to spawn eggs, this behavior was most likely induced by the stress of collection and maintenance under abnormal conditions (Wilson 1888), and free gametes were never observed in the course of this study.

Both histological examination of reproductive tissues and direct observation of living colonies in the field and laboratory were used to address the following questions: (1) What is the timing of reproduction of Manicina areolata populations from Caribbean Panama? (2) At what size and age do colonies of $M$. 
areolata become reproductive? (3) Is fecundity correlated with colony size? (4) Does fecundity vary among populations, and how is planula production related to population recruitment rates? (5) How long are larvae brooded, and how soon after release do they settle? (6) On what spatial and temporal scales do reproductive characters remain constant?

\section{MATERIALS AND METHODS}

Study sites. Five large populations from a range of environments adjacent to San Blas Point (northeast Panama) were selected for study (Fig. 1). These included seagrass-dominated back-reef habitats (Korbiski, Aguadargana), a wave-swept red algal/rubbledominated environment (Point), a more sheltered sediment-rich mangrove fringe (Ulagsukun), and a very shallow back-reef flat exposed to high wave energy (Barrier). Population densities in all localities were high ( 1 to 10 colonies $\mathrm{m}^{-2}$ ), and populations extended over thousands of square meters.

Planula capture. From November 1989 to May 1990, approximately 50 colonies were collected from each locality every 10 to $20 \mathrm{~d}$. The colonies were quickly transported in covered buckets to a flow-through aquarium system. Samples of 30 to 40 colonies were maintained together in a series of aquaria, and effluent from each tank was filtered through $125 \mu \mathrm{m}$ plankton netting larvae traps. Aquaria and traps were inspected approximately every $6 \mathrm{~h}$ for the presence of larvae. Larvae were never found in the effluent of the control without corals.

To determine the condition of gonads, samples of colonies were examined monthly from April to August.

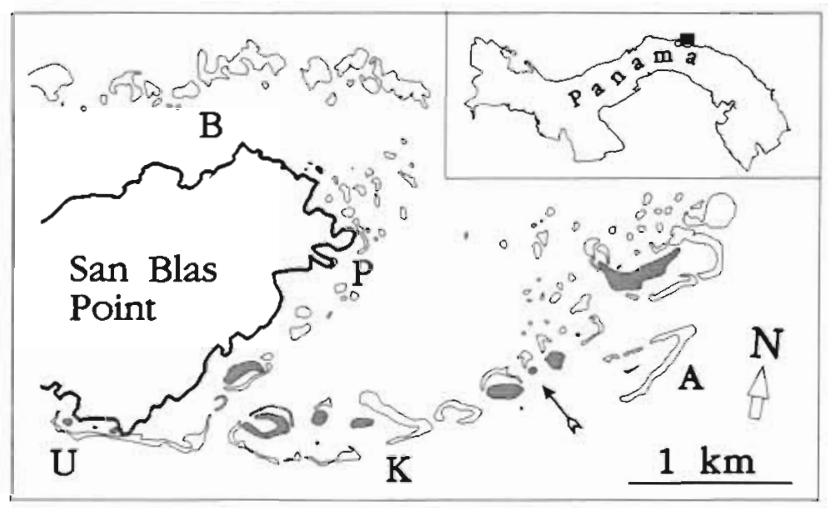

Fig. 1. Location of Manicina areolata study populations in the San Blas Islands, Panama. Thin arrow marks the Smithsonian Tropical Research Institute's San Blas Field Station, shaded areas indicate low islands, blank outlined areas indicate reefs. $\mathrm{A}=$ Aguadargana, $\mathrm{K}=$ Korbiski, $\mathrm{U}=$ Ulagsukun, $\mathrm{P}=$ = Point, $B=$ Barrier (map after Robertson 1987)
Each colony was fixed for 6 to $8 \mathrm{~h}$ in $10 \%$ formalin in seawater, washed in fresh water and split with a chisel to expose mesenteries. Mesenteries were examined with the aid of a dissecting microscope, and the presence or absence of gonads or larvae was scored for each colony.

After planulation had been detected (June 18, 1990), collected colonies were maintained in individual plastic containers with plankton net walls (Jokiel 1985). Aquarium space was limited, so to abtain large samples for within- and between-population comparisons, collections of colonies were made only from the Aguadargana and Korbiski populations. Swimming larvae were counted by removing them from the filter containers with a $10 \mathrm{ml}$ serological pipette, and attached planulae were counted in place. Each container was cleaned after counting to remove newly attached juveniles. Colonies were collected on June 18 (4 d before the new moon), July 6 ( 2 d prior to full), July 15 (last quarter), August 9 (near full) and August 16 (last quarter). Half of the previously maintained corals were examined under a dissecting microscope for gonads and larvae. The others were returned to marked areas of their original habitats and were not re-sampled. Six of the colonies that shed larvae during June and 40 which released planulae in July were kept under observation until the end of August.

Histology. Between 20 and 50 colonies were collected on June 25 and 26 (first quarter moon following the June new moon), and daily from July 16 (last quarter) until July 25 ( $3 \mathrm{~d}$ after the July new moon). All colonies were fixed overnight in $10 \%$ formalin in seawater, rinsed in fresh water, and stored in $70 \%$ ethanol. Decalcification was accomplished in $7 \%$ nitric acid with $1 \%$ EDTA added as a chelating agent, and entire colonies were embedded in paraffin using an Autotechnicon tissue processing machine. Trimmed portions of the colonies were sectioned to $7 \mu \mathrm{m}$ using an A/O microtome. Replicate samples from 5 colonies allowed estimation of intra-colony variation in reproductive state. Sections were stained with Gill's Hematoxylin and Eosin, and scored for the presence, relative abundance, and condition of gonads and planulae.

Colony size. Colony height, length, and width were measured to the nearest tenth of a millimeter on all collected colonies using dial calipers. Height was measured from the base of the stalk to the most elevated part of the oral surface. Colony length is the maximum dimension of the corallum and width is maximum dimension perpendicular to the length. The samples were divided into size classes by rounding colony height to the nearest $5 \mathrm{~mm}$. Five millimeters is approximately the mean annual extension rate measured for these populations using alizarin stain techniques (Johnson 1991, in press). 


\section{RESULTS}

\section{Gonads}

Descriptions of the reproductive structures and gametogenesis within Manicina areolata have been previously reported (Wilson 1888, Peters 1978, 1984), and are beyond the scope of this study. Accumulations of reproductive cells ('gonads') were located within mesenteries below the attachment of mesenterial filaments (Fig. 2). Both ovaries and spermaries were present in the same mesentery, and no exclusively female or male colonies were found.

Examination of reproductive structures indicates that the planulation season of Manicina areolata in
Fig. 2. Manicina areolata. Photomicrographs of reproductive structures. (a) Planulae (p) within a colony collected at new moon, showing that larvae have developed 2 mesenteries $(\mathrm{m})$ at the time of release; and (b) gonads 1 mo prior to planulae release (collected June 26). Ovaries (o) are large with well-defined nuclei (n), and spermaries (s) are abundant with hollow centers. Scale bars $=0.25 \mathrm{~mm}$
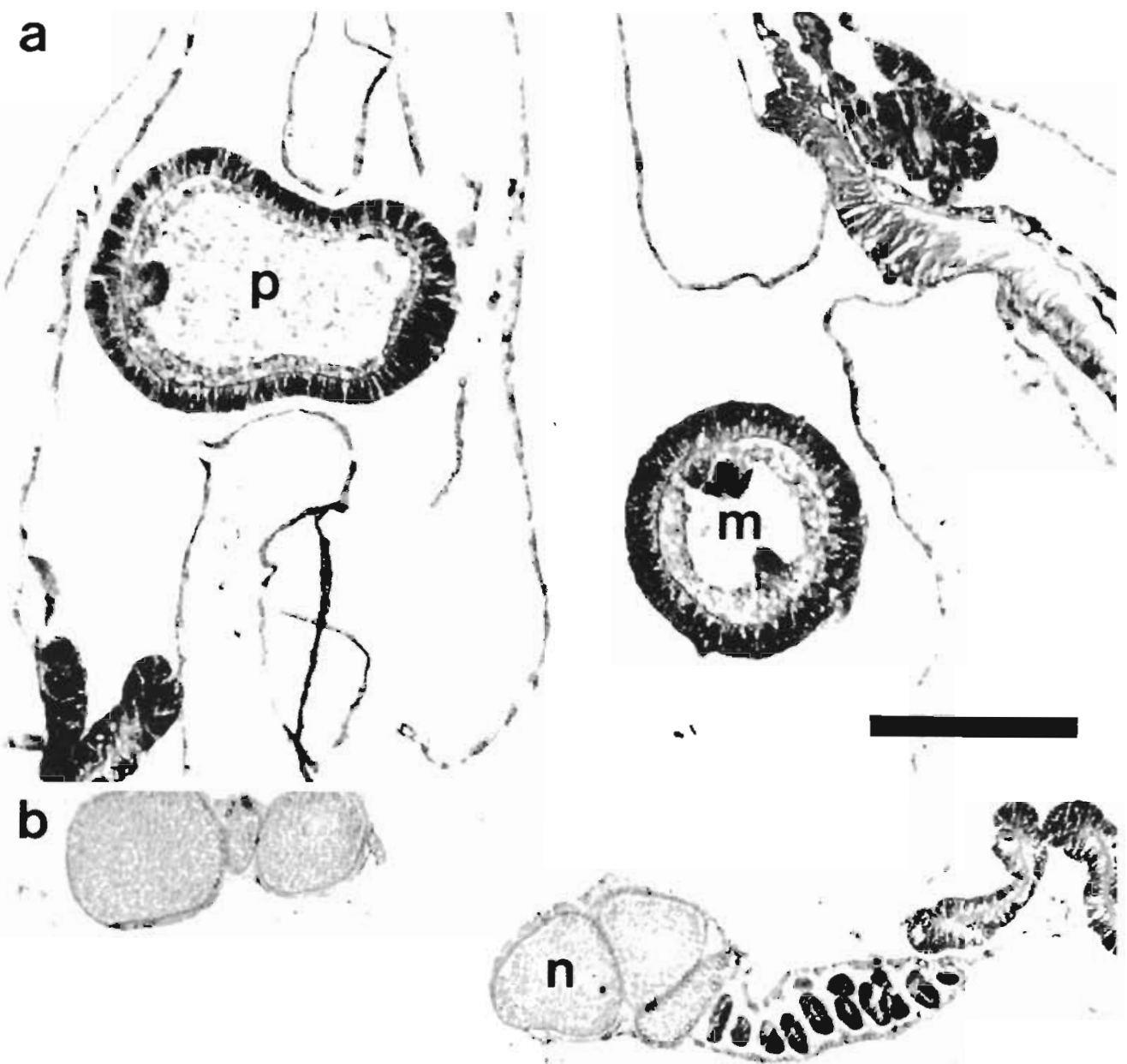

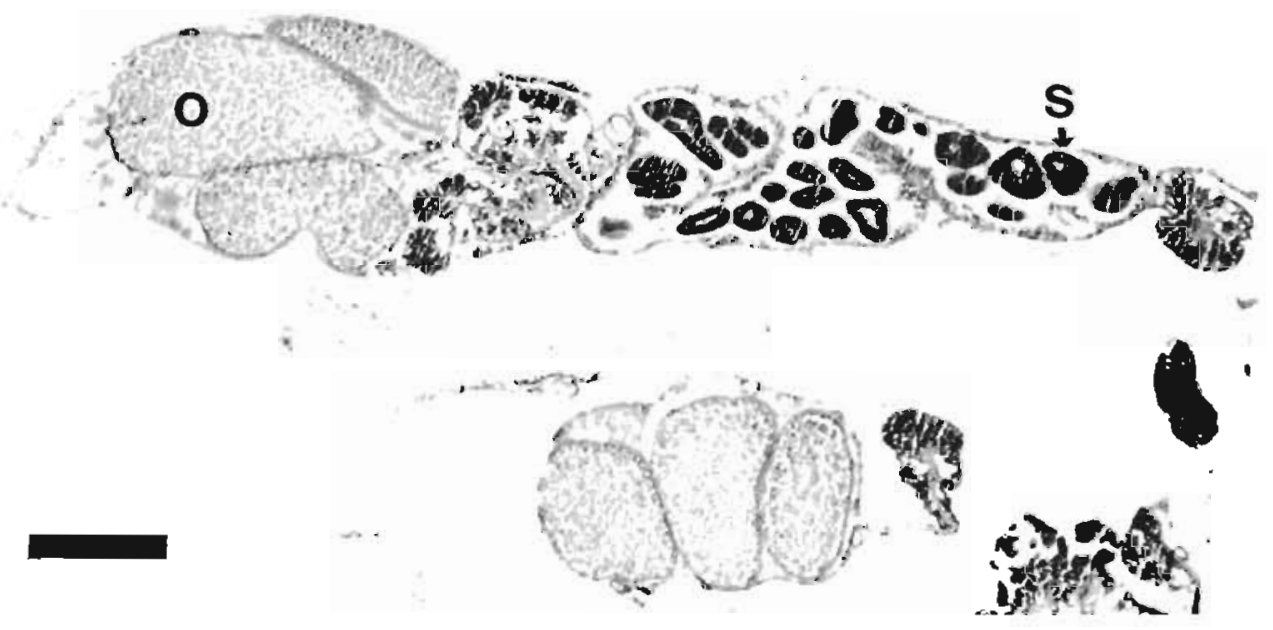



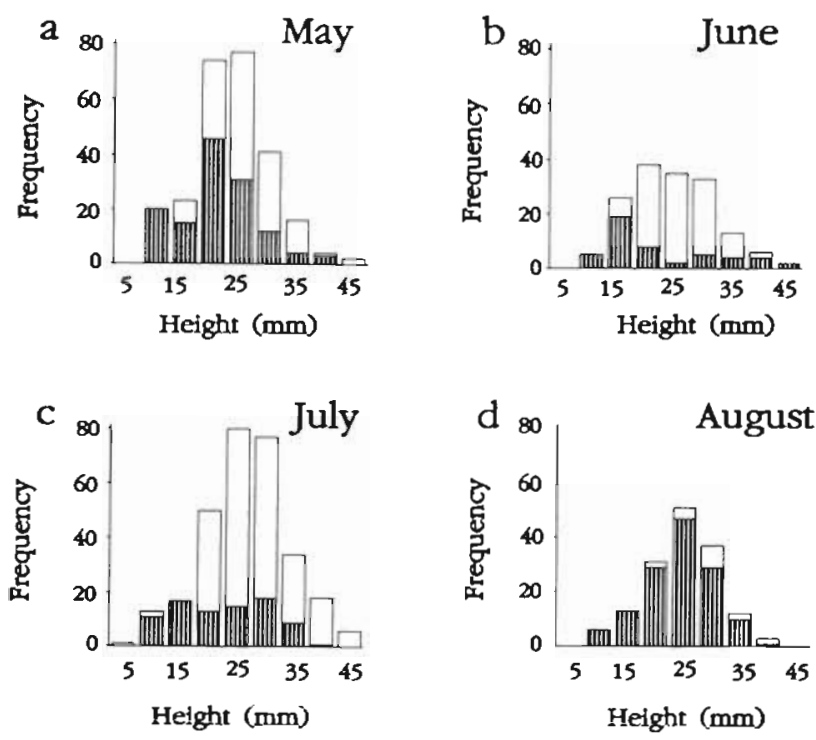

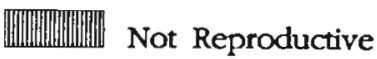

\section{Reproductive}

Fig. 3. Manicina areolata. Relationship between colony size and reproductive state, May through August 1990. Dissected colonies that possessed visible gonads or planulae were scored as reproductive

the San Blas region began in June and ended in July (Fig. 3). At the last quarter moon of May 1990, $90 \%$ of those colonies greater than $20 \mathrm{~mm}$ in height possessed visible gonads. By August, few colonies possessed gonads which were visible under a dissecting microscope. Histological results confirmed these observations. Twenty-three of the $30(77 \%)$ colonies collected after the June new moon were fertile (possessed either gonads or planulae), while only 2 colonies $(4 \%)$ col-

Table 1. Manicina areolata. Results of histological examination during summer 1990. Colonies with many planulae possessed more than 25 in a typical section. New moon fell on the nights of June 22 and July 22, full moon on July 8

\begin{tabular}{|lcccccc|}
\hline Date & $\mathrm{n}$ & Gonads & $\begin{array}{c}\text { Gonads \& } \\
\text { planulae }\end{array}$ & \multicolumn{2}{c}{ Planulae } & Few \\
& & & Many & Noproductive \\
\hline June 25 & 21 & 11 & 4 & 1 & 3 & 2 \\
June 26 & 9 & - & - & - & 4 & 5 \\
July 16 & 9 & - & - & 7 & - & 2 \\
July 17 & 5 & - & - & 4 & - & 1 \\
July 18 & 5 & - & - & 2 & 2 & 1 \\
July 19 & 5 & - & - & 4 & - & 1 \\
July 20 & 5 & 1 & - & 3 & - & 1 \\
July 21 & 5 & - & - & 3 & 1 & 1 \\
July 22 & 5 & - & - & - & 4 & 1 \\
July 23 & 5 & 1 & - & - & 2 & 2 \\
July 24 & 5 & - & - & - & 5 & - \\
July 25 & 5 & - & - & - & 4 & 1 \\
\hline
\end{tabular}

lected after July 16 possessed gonads (Table 1). The presence of both gonads and planulae in colonies collected in late June suggests that some colonies may planulate during both lunar months. Although the sampling scheme did not allow the precise determination of timing of gametogenesis or fertilization, planulae were abundant in the gastric cavities of most of the colonies by July 16 . Thus, most fertilization is likely to have occurred after the first quarter (June 29) and prior to the last quarter (July 15) lunar phase. The absence of large numbers of planulae in colonies collected after July 22 (Table 1) suggests that most planulae were released on a few nights near the new moon.

\section{Timing of planulae release}

Planulae were first seen swimming in the filters on June 19 (Fig. 4), and were produced by 5 to $15 \%$ of the total number of colonies for the next $6 \mathrm{~d}$. The planulae were released continuously between 02:00 and 05:00 $\mathrm{h}$, during the darkest part of the night. Planulation was synchronous in the 2 populations. One colony continued to produce small numbers of larvae until June 29, and another colony released a total of 50 planulae during the nights of June 30 and July 1 . Except for this colony, no planulae were liberated until July 19,3 nights prior to the July new moon. During the June event, a total of 14115 planulae were counted, released from $20.5 \%(n=102)$ of the colonies. The pattern of planulation in July was similar to that observed during the June event. Increasing numbers of colonies produced increasing numbers of larvae and the peak of reproductive activity fell within $24 \mathrm{~h}$ of the new moon. The July event was more pronounced, however, with more than 55000 planulae released from $93 \%$ $(\mathrm{n}=123)$ of the colonies. Ninety-nine percent $(n=59290)$ of the planulae shed during this lunar cycle were released within a few days of the new moon. The timing of planulation was associated with monthly tidal maxima for the region, and occurred several hours after high tide (U.S. Department of Commerce 1990). No planulae were released during the August 1990 new moon, and the monitoring was terminated on August 23.

Colonies which released planulae during June and were maintained in individual containers for a total of $6 \mathrm{wk}$ released planulae again in July. Production was much lower (166 planulae from $6 \mathrm{col}$ onies) than for colonies collected on the last quarter moon (July 15) and maintained for $7 \mathrm{~d}$ before planulating. 
a

b
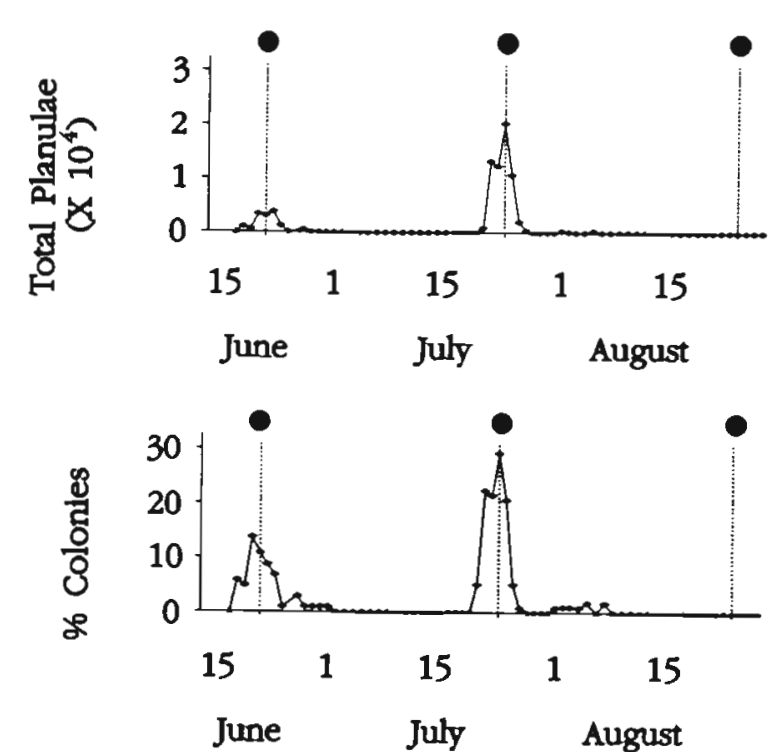

C

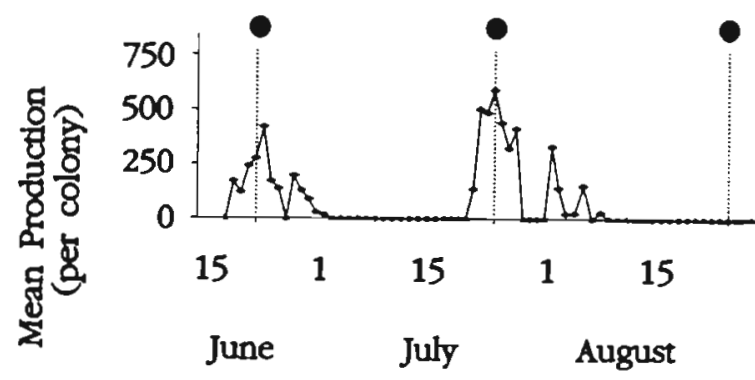

Fig. 4. Manicina areolata. Timing of planulae release during summer 1990. (a) Total planulae released by all observed colonies ( $n=102$ colonies from June 18 to July 7 and 116 colonies thereafter); (b) percent of observed colonies that released larvae; and (c) number of planulae produced per colony during each day. The beginning of each lunar cycle (new moon) is indicated by vertical lines

\section{Size and fecundity}

Small colonies were much less likely to be reproductive than large colonies (Fig. 3). A colony height of approximately 15 to $20 \mathrm{~mm}$ was required for a colony to be reproductive. This size corresponded with an approximate age of 2 to 3 yr (Johnson 1991, in press). No detectable differences were found among the populations in colony size at age of first reproduction.

The distribution of planulae production during the July event was highly skewed, with the majority of colonies producing hundreds, and only a few releasing thousands of larvae (Fig. 5). The 7 (10.6\%) most fecund corals from Aguadargana released 18599 $(40.7 \%)$ of the planulae produced by that population. These colonies were similar in morphology to the less fecund colonies and there was no relationship between number of planulae and colony size after colonies become mature at a size of approximately $15 \mathrm{~mm}$ (Fig. 6; Spearman rank correlation coefficient between colony size and planula production $=-0.044$, $\mathrm{n}=126, \mathrm{p}=0.63$ ).

Colonies from the Aguadargana population released more planulae than those from Korbiski (45739 counted from 66 colonies from Aguadargana and 13551 from 57 colonies from Korbiski). To some extent, this difference is a result of a few highly fecund colonies in the Aguadargana population, but an analysis of variance of log-transformed data indicates significant differences between the 2 localities $(F=8.82$; $\mathrm{df}=1,124 ; \mathrm{p}=0.0036$ ).

\section{Planula behavior}

Planulae range from 0.25 to $0.5 \mathrm{~mm}$ in length when released, and have developed one pair of mesenteries. They possess both zooxanthellae and well-developed stomodea, and so may obtain energy through both photosynthesis and heterotrophy. They are active swimmers near the surface and in the water column,
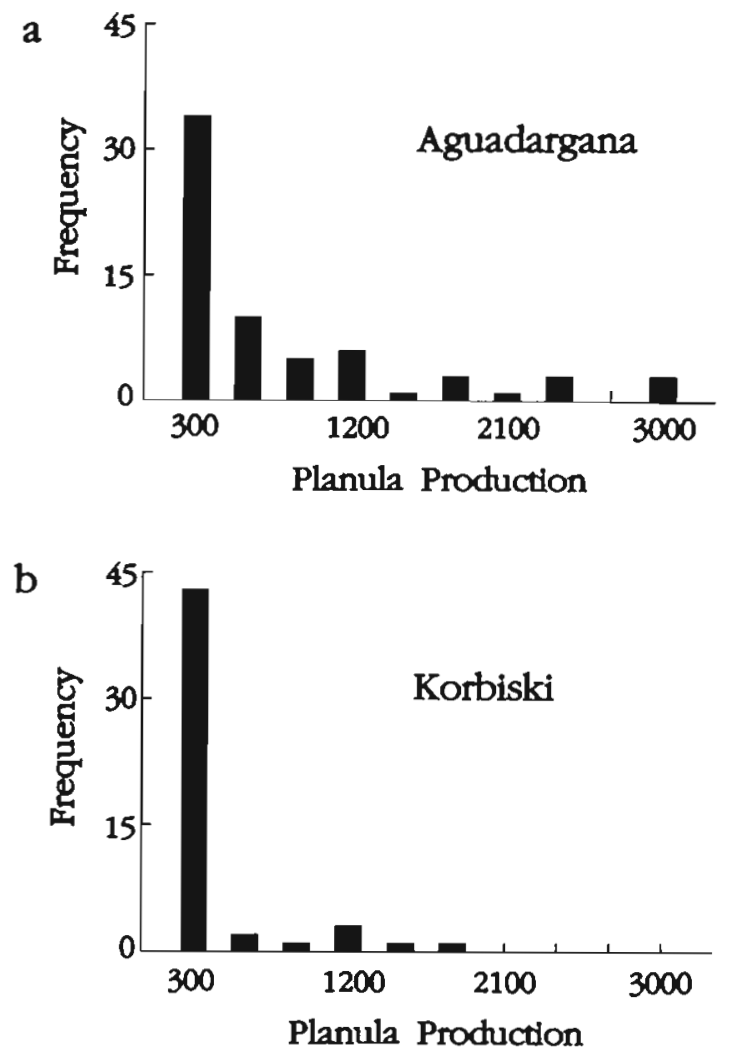

Fig. 5. Manicina areolata. Distribution of colony planula production during July swarming event for Aguadargana and Korbiski. Frequency distributions are strongly skewed to the right, with most colonies releasing hundreds of larvae. Highly fecund colonies were more common in Aguadargana 
a

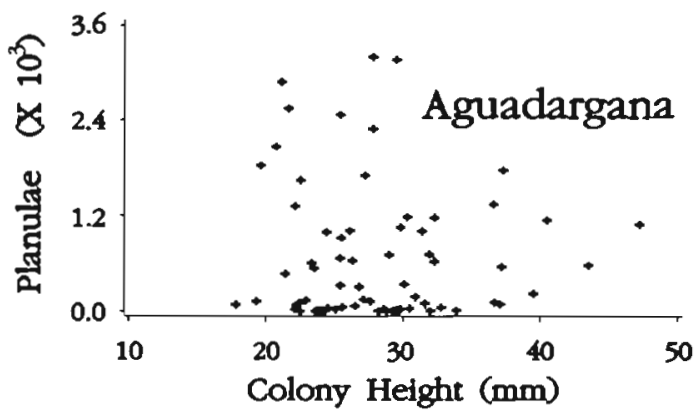

b

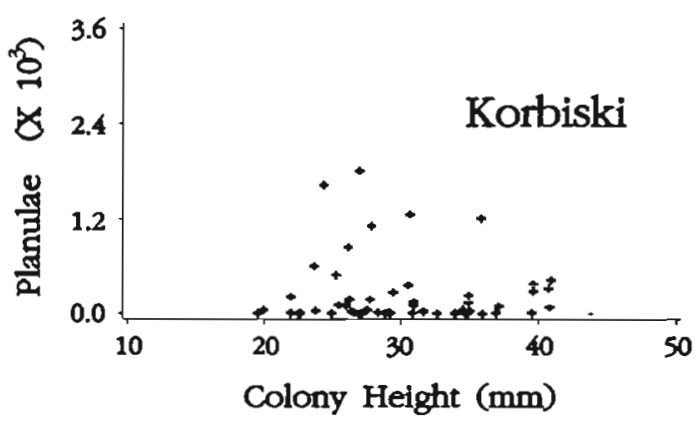

Fig. 6. Manicina areolata. Colony size and planula production within the 2 populations. Production is variable, and there was no correlation between fecundity and size for colonies greater than 15 to $20 \mathrm{~mm}$ in height. Smaller colonies were not reproductive and were not included in the planula capture experiment

but many spent considerable time swimming near or crawling on the bottom of the dish. The planulae were quick to settle - many attached to the walls and base of the experimental containers and especially on the aboral surface of the parental colony within $6 \mathrm{~h}$ of release. Approximately $50 \%$ of the planulae settled within the first $24 \mathrm{~h}$. The remainder failed to settle and died within 2 wk of release. These results suggest that if a suitable settlement site is available (such as the underside of the parental colony), planulae will rapidly settle, but they are able to live several weeks without settling.

Settlement patterns appeared non-uniform, with preferential settlement near the edges of the aquaria. Settlement was gregarious, with many planulae apparently selecting sites near previously settled larvae. Walls were not always well developed between contiguous juveniles, suggesting some fusion among individuals. In other cases, well-developed walls were erected, and adjacent juveniles began to overtop one another.

\section{DISCUSSION}

Recent reviews of coral reproduction (e.g. Richmond \& Hunter 1990) have included listings for
Meandrina ( $=$ Meandra) areolata within the Family Meandrinidae in summarizing the early studies of Boschma (1929) and Yonge (1936). Judging from their figures, the authors were working with the taxon now included in the genus Manicina (see Cairns 1982), and their results should be included with the more recent studies of Manicina areolata (Linneaus) within the Faviidae.

\section{Seasonality}

Previous studies of the timing of reproduction of Manicina areolata in different parts of the Caribbean report differing results. Wilson (1888) was first to document a reproductive season of March and April for populations in the Bahamas in 1887. Boschma (1929) observed $M$. areolata planulae at the Tortugas Lab (south Florida, USA) during a new moon in July 1925 , and Yonge (1936) observed planulae release at Tortugas for a few days prior to the July and August new moons of 1934. In south Florida, planulae were produced during the late summer and early fall (Peters 1978), and in Belize, no gonads were visible under a dissecting microscope in May 1989 (Johnson unpubl. data). The differences between seasonality in Panama and that reported in studies from the eastern Caribbean may reflect regional or annual variation in reproductive season (Richmond 1987), in contrast to regional similarity in reproductive season reported for other Caribbean species (Soong 1991, Szmant 1991). No large-scale regional trends are evident, since both the earlier and later reproductive seasons have been reported from the northeast Caribbean. The wide range of local environmental conditions across the Caribbean argues against environmental factors such as water temperature, tidal conditions, or nutrient availability as causes of seasonality in reproduction. At present, neither reproductive nor environmental data exist to test explanations for this variation within the Caribbean province.

\section{Synchrony}

Three selective mechanisms have been proposed to explain the synchronous release of larvae. Two regard environmental cues as forcing mechanisms, and the third focuses on the inherent benefits of synchronous planulation regardless of the timing. First, release of planulae at the tidal maxima correlated with lunar phase can facilitate dispersal of propagules. In this study, planulae were ejected as tides fell, tending to wash larvae away from the parent populations and thereby maximizing dispersal. However, in the case of 
Manicina areolata, it is unclear what advantages are to be gained from dispersal, since previous study has shown that larvae tend to settle quickly, and populations are likely to be self-seeded (Johnson 1991, in press). If Stimson's (1978) hypothesis that shallowwater species are more likely to brood larvae to assure short dispersal is correct, then release of larvae during tidal minima would be an appropriate strategy for $M$. areolata.

The other 2 hypotheses proposed as adaptive explanations for synchronous planulation focus on the role of predation. It is likely that larval predation is a significant selective mechanism acting on coral reproduction, since coral recruitment is always orders of magnitude less than population reproductive output (Babcock 1991). Many potential predators detect prey visually, so larvae would be more likely to survive if released on dark nights, and the lunar cycle results in predictable patterns of nocturnal illumination. Experimental manipulation of the nocturnal light regime has been used to demonstrate that night illumination provides the cue for synchronous planulation in Pocillopora damicornis (Jokiel et al. 1985).

A second predation-related hypothesis is that synchronous planulation could overwhelm predators and maximize larval survivorship. The predator satiation hypothesis rejects the notion of any adaptive value to the specific timing of a planulation event; it is the synchrony itself that is adaptive, and the lunar cycle would provide a predictable cue.

An even stronger possibility is that synchronous spawning of sperm and fertilization could be the proximate cause of synchronous planulation, and simultaneous larval release only a secondary consequence of adult behavior (Szmant-Froelich et al. 1985, Robertson et al. 1990). A more detailed examination of the timing of gametogenesis in Manicina areolata is required to test this hypothesis, but other Caribbean corals spawn gametes in phase with a lunar cycle (Chornesky \& Peters 1987, Szmant 1991), and release of sperm in $M$. areolata did occur sometime between first and last quarter moons of June and July.

Only long-term regional studies and experimentation will allow detection of possible adaptive causes for seasonality and synchrony of coral breeding. One such study found differing planulation schedules at different geographic locations and different years of Pocillopora damicornis (Richmond \& Jokiel 1984). They suggested that timing of reproduction is a character of taxonomic significance, and this result may reflect species recognition problems within the group. Thus, timing of reproduction may provide a useful character for coral species recognition, especially in groups where detailed morphometric or biochemical analyses are not yet available.

\section{Fecundity}

Planula production was estimated only during the July new moon and therefore underestimates annual production per colony. However, 4 times as many colonies released planulae in July than in June, so most colonies reproduce only in July. In general, planula production is a more accurate estimate of fecundity than estimates of gonad volume measured on histological sections because it eliminates the problem of subsampling and intracolony variation in reproduction condition (Chornesky \& Peters 1987).

Variation in planula production has been reported for other corals (cf. Harrigan 1972, Rinkevich \& Loya 1979, Richmond \& Jokiel 1984), and may be related to differential reproductive allocation (Richmond 1987), fertilization success, or the general health of the colony. However, little is known about evaluating the level of stress experienced by a reef-coral (Grigg \& Dollar 1990), and to date no estimate of fertilization success for a brooding coral has been documented. Differences in fecundity within populations most likely reflect annual variation in local hydrodynamic patterns during sperm release. Production of a limited number of larvae from colonies maintained in the laboratory during both June and July suggests that self-fertilization in Manicina areolata is possible, but may also be attributed to a limited number of sperm moving into the flow-through system. Colonies which were fertilized in the field, but still produced small numbers of planulae, similarly may have not received enough sperm to fertilize each ripe egg. All colonies produced orders of magnitude more sperm than eggs, but both developing larvae and apparently normal unfertilized eggs were present in a significant proportion of the colonies during the last quarter of the lunar month. This suggests that larval production is limited by sperm availability in $M$. areolata and selffertilization is not common (Szmant-Froelich et al. 1985).

The positive skewed distribution in planulae production is significant in that during the study year, very few colonies are dominating population larval production. This variation most likely results from small-scale variation in reproductive success, and not from the long-term domination by large colonies hypothesized for massive reef corals (Potts et al. 1985). Such extreme spatial variation among apparently healthy colonies on a scale of meters highlights the fact that the reproductive output of populations can only be estimated from well-designed sample schemes. The range of temporal and spatial scales over which ecological processes shape reef-coral population decreases the usefulness of short-term studies in the detection of significant patterns (Jackson 1991, Done 1992). 
The axiomatic relationship between colony size and reproductive output of mature colonies is based on both increasing numbers of polyps and increased polyp fecundity (Babcock 1984). The lack of a significant relationship between planula production and colony size in mature Manicina areolata from Panama most likely reflects both the high variability of individual production and the small size range of colonies characteristic of the study populations. Without considering the relationship between colony size and the number of eggs produced per mesentery, larger colonies certainly possess more mesenteries and therefore produce more gametes. However, variation in reproductive success (fertilization) swamps variation in gamete production within these localities.

\section{Reproductive strategy}

The results presented here agree well with the prediction of a correlation between colony size, age at first reproduction, and environmental disturbance (Szmant 1986, 1991, Harrison \& Wallace 1990). The proposed explanation is that the smaller colonies tend to live in environments with a high frequency of disturbance, so the potential fitness gained by investment in growth is offset by the probability of total colony mortality. Therefore, young colonies reproduce early with the potential cost of decreased growth rate. Manicina areolata lives in back-reef seagrass flats and mangrove fringe environments, habitats which are extremely susceptible to disturbance including temperature and salinity changes as well as waves and a high likelihood of burial. Indeed, colony survivorship increases after colonies grow to a height of 15 to $20 \mathrm{~mm}$, the size at which sexual reproduction is initiated (Johnson 1991, in press), suggesting that resources are allocated to reproduction only after a colony grows large enough to escape a high probability of mortality.

The presence of a brief reproductive season in Manicina areolata conflicts with generalizations that small brooding species reproduce throughout the year (Harrison \& Wallace 1990, Soong 1990). Favia fragum (Esper) is another Caribbean faviid which is common in the sediment-rich shallow environments characteristic of $M$ areolata. If environmental factors are important in structuring the reproductive characteristics of populations, then these 2 taxa should employ similar reproductive strategies. Both species are simultaneous hermaphrodites with brooded larvae (Szmant-Froelich et al. 1985), and both species begin to reproduce within 2 or 3 yr. However, F. fragum reproduces throughout the year, producing a few large eggs, while $M$. areolata breeds for only a few months each year and typically produces a larger number of smaller eggs. Therefore, although the 2 taxa live in similar habitats, 2 unique reproductive strategies have originated. Caution should be used in ascribing broad adaptive significance to general reproductive characteristics.

Acknowledgements. Field work was completed with a predoctoral fellowship from the Smithsonian Tropical Research Institute with support from N. Knowiton and J. B. C Jackson. J. Maté and D. Calvillo assisted in the field. Histological facilities and the help of $\mathrm{K}$. Walters at the University of Lowa Central Electron Microscope Research Facility are also acknowledged. Suggestions on drafts of this manuscript were made by $\mathrm{A}$. Budd, N. Knowlton, and 2 anonymous reviewers. Thanks also to the Kuna People and the government of the Republic of Panama for permission to work in the San Blas.

\section{LITERATURE CITED}

Babcock, R. C. (1984). Reproduction and distribution of two species of Goniastrea (Scleractinia) from the Great Barrier Reef Province. Coral Reefs 2: 187-195

Babcock, R. C. (1991). Comparative demography of three species of scleractinian corals using age- and size-dependent classifications. Ecol. Monogr. 61(3): 225-244

Boschma, H. (1929). On the postlarval development of the coral Maeandra areolata (L.). Carnegie Inst. Washington, Pap. Tortugas Lab. 26: 129-147

Cairns, S. D. (1982). Stony corals (Cnidaria: Hydrozoa, Scleractinia) of Carrie Bow Cay, Belize. In: Rutzler, K. MacIntyre, I. G. (eds.) The Atlantic barrier reef ecosystem at Carrie Bow Cay, Belize, I. Smithson. Contr. mar. Sci. 12: $271-302$

Chornesky, E. A., Peters, E. C. (1987). Sexual reproduction and colony growth in the scleractinian coral Porites astreoides. Biol. Bull. 172: 161-177

Done, T J. (1992). Constancy and change in some Great Barrier Reef coral communities: 1980-1990. Am. Zool. (in press)

Grigg, R. W., Dollar, S. J. (1990). Natural and anthropogenic disturbance on coral reefs. In: Dubinsky, Z. (ed.) Ecosystems of the world 25: Coral reefs. Elsevier, Amsterdam, p. 439-452

Harrigan, J. (1972). The planula larva of Pocillopora damicornis; lunar periodicity of swarming and substratum selection behavior. Ph.D. dissertation, Univ. of Hawaii, Honolulu

Harrison, P. L., Wallace, C. C. (1990). Reproduction, dispersal and recruitment of scleractinian corals. In: Dubinsky, $Z$. (ed.) Ecosystems of the world 25: Coral reefs. Elsevier, Amsterdam, p. 133-207

Hughes, T P., Jackson, J. B. C. (1985). Population dynamics and life histories of foliaceous corals. Ecol. Monogr. 55(2) $141-166$

Jackson, J. B. C. (1991). Adaptation and diversity of reef corals. Bioscience 41: 475-482

Johnson, K. G. (1991). Population ecology of a free-living coral: reproduction, population dynamics, and morphology of Manicina areolata (Linneaus). Ph.D. dissertation, Univ. of Iowa, Iowa City

Johnson, K. G. (in press). Population dynamics of a free-living coral: recruitment, growth, and survivorship of Manicina areolata (Linneaus) on the Caribbean coast of Panama. J. exp. mar. Biol. Ecol. 
Jokiel, P. L. (1985). Lunar periodicity of planula release in the reef coral Pocillopora damicornis in relation to various environmental factors. Proc. 5th Int. Coral Reef Congr., Tahiti 4: 307-312

Jokiel, P. L., Ito, R. Y., Liu, P. M. (1985). Night irradiance and synchronization of lunar release of planula larvae in the reef coral Pocillopora damicornis. Mar. Biol. 88: 167-174

Peters, E. C. (1978). Effects of long-term exposure of the coral Manicina areolata (Linne, 1758) to water-soluble oil extracts. M.Sc. thesis, Univ. of South Florida, St Petersburg

Peters, E. C. (1984). A survey of the normal and pathological histology of scleractinian corals with emphasis on the effects of sedimentation stress. Ph.D. dissertation, Univ. of Rhode Island, Kingston

Potts, D. C., Done, T. J., Isdale, P. J., Fisk, D. A. (1985) Dominance of a coral community by the genus Porites (Scleractinia). Mar. Ecol. Prog. Ser. 23: 79-84

Richmond, R. H. (1987). Energetic relationships and biogeographical differences among fecundity, growth and reproduction in the reef coral Pocillopora damicornis. Bull. mar. Sci. 41(2): 594-604

Richmond, R. H., Jokiel, P. L. (1984). Lunar periodicity in larva release in the reef coral Pocillopora damicornis at Enewetak and Hawaii. Bull. mar. Sci. 34(2): 280-287

Richmond, R. H., Hunter, C. L. (1990). Reproduction and recruitment of corals: comparisons among the Caribbean, the Tropical Pacific, and the Red Sea. Mar. Ecol. Prog. Ser 60: $185-203$

Rinkevich, B., Loya, Y (1979). The reproduction of the Red Sea coral Stylophora pistillata. II. Synchronization in breeding and seasonality of planulae shedding. Mar. Ecol. Prog. Ser. 1: 145-152

This article was submitted to the editor
Robertson, D. R. (1987). Responses of two coral reef toadfishes (Batrachoididae) to the demise of their primary prey, the sea urchin Diadema antillarum. Copeia 1987: 637-642

Robertson, D. R., Petersen, C. W., Brawn, J. D. (1990). Lunar reproductive cycles of benthic-brooding reef fishes: reflections of larval biology or adult biology? Ecol. Monogr. 60: 311-329

Soong, K. (1990). Reproduction of colonial reer corals; individuality of coral colonies and colony size-related characters Ph.D. dissertation, Univ. of Texas, Austin

Soong, K. (1991). Sexual reproductive patterns of shallowwater reef corals in Panama. Bull. mar. Sci. 49:832-846

Stimson, J. S. (1978). Mode and timing of reproduction in some common hermatypic corals of Hawaii and Enewetak Mar. Biol. 48: 173-184

Szmant, A. M. (1986). Reproductive ecology of Caribbean reef corals. Coral Reefs 5: 43-54

Szmant, A. M. (1991). Sexual reproduction by the Caribbean reef corals Montastraea annularis and $M$. cavernosa. Mar Ecol. Prog. Ser. 74: 13-25

Szmant-Froelich, A. M., Reutter, M., Riggs, L. (1985). Sexual reproduction of Favia fragum (Esper): lunar patterns of gametogenesis, embryogenesis and planulation in Puerto Rico. Bull. mar. Sci. 37: 880-892

U.S. Department of Commerce (1990). Tide Tables 1990 , high and low water predictions, east coast of North and South America. U.S. Dept of Commerce, Washington, D.C.

Wilson, H. V. (1888), On the development of Manicina areolata. J. Morph. 2: 191-252

Yonge, C. M. (1936). Studies on the biology of Tortugas corals: 1. Observations on Meandra areolata Linn. Carnegie Inst Washington, Pap. Tortugas Lab. 29: 187-198

Manuscript first received: January 23, 1992

Revised version accepted: September 17, 1992 